\title{
Are Tattooing Indicators of Dark Personalities? An Analysis of Body Modification within the Framework of Dark Triad of Personality
}

\author{
Dan Florin Stanescu, Marius C. Romascanu \\ National University of Political Studies and Public Administration, Romania \\ dan.stanescu@comunicare.ro, marius.romascanu@comunicare.ro
}

\begin{abstract}
There are several displays commonly labeled as body modifications, including body piercings, scarification, tattoos, cutting, etc. In this study, we were focused on one distinct form of body modification, namely tattoos. The current exploratory study investigated the connection between body modifications (BM) and Dark Triad personality for a sample of 77 university students with BM, compared to a control group of 77 non-BM individuals. Three self-administrated questionnaires were used to collect the data: Self-Report Psychopathy Scale-Short Form, Mach-IV scale, and Narcissistic Personality Inventory. The findings suggest that subclinical psychopathy is most strongly connected to body modifications. An increased number of tattoos was also significantly correlated with a higher level of anti-sociality. Participants with visible body modifications had significantly higher affective callousness and overall self-reported subclinical psychopathy levels, compared with individuals with non-visible alterations.
\end{abstract}

Keywords: Body modifications; narcissism; dark triad; subclinical psychopathy; Machiavellianism; tattoo

\section{Introduction}

Body Modification, Rebellion against Mainstream Values, and Self-Construction: The term body modification (BM) refers to several procedures that change the appearance of one's body. There are several displays commonly labeled as body modification, including body piercings, scarification, tattoos, cutting, adornments, garments, and hairstyles (Myers, 1992). In this study, we will focus on one distinct form of body modification, namely tattoos. Throughout time, a shift has occurred in the way body modification was perceived and, consequently, a shift in the social and psychological significance that possessors of BM attribute to their tattoos. Early studies have found that owning a tattoo correlated positively with personality disorders (Post, 1968), antisocial behavior (Favazza, 1996), and risk-taking behavior (Braithwaite, Robillard, Woodring, Stephens, \& Arriola, 2001), (Roberts, Auinger, \& Ryan, 2004), (Caroll, Riffenburg, \& Myhre, 2002), (Deschesnes, Fines, \& Demers, 2006), while several studies linked BM to psychopathy (Post, 1968), and various psychiatric conditions (Raspa \& Cusack, 1990). The mainline of reasoning to explain such findings is closely linked to the cultural history of body modifications, which were initially mostly found within certain social groups considered to have an aggressive or criminal behavioral background (e.g., bikers, military, sailors, prison inmates); these BM markings served as an indicator of rebellion against mainstream/conservative cultural values (DeMello, 2003).

A recent study found that individuals with tattoos had significantly higher levels of reactive rebelliousness, anger, and verbal aggression than non-tattooed adults, but did not have significantly higher levels of proactive rebelliousness, physical aggression, and hostility (Swami, et al., 2015). The authors suggest that stereotypes regarding tattooed individuals are outdated. Several authors maintain that body modifications such as tattoos and piercings have entered the mainstream (Tate \& Shelton, 2008), (Rooks, Roberts, \& Scheltma, 2000), appearing less infringe/special social groups. For example, in a study conducted in the U.S.A. in 2008, Tate \& Shelton (Tate \& Shelton, 2008) found that up to $25 \%$ of middle-class college students possessed permanent tattoos, prompting the authors to argue against considering tattoos signs of social deviance or personality flaws. In 2007 , it was estimated that roughly $10 \%$ of the population in modern western societies have some form of body modification (Wohlrab, Stahl, Rammsayer, \& Kappeler, 2007). A 2006 survey conducted in Germany showed that the presence of tattoos for the general population was 8.5\% (Stirn, Hinz, \& Brahler, 2006). Based on the evidence of their wide prevalence in the general population, we could argue that BM has become less likely to be correlated with such antisocial personality traits as those listed above. Investigating the personality correlates of body modifications in an Eastern European setting is relevant. 
Considering that Romania has more traditional cultural values that determine the norms for selfpresentation. Moreover, this investigation is useful to help bridge the geographical divide in the research on this topic, as there is little data about the psychological correlates of BM from studies conducted outside the Western European or North American cultural settings. Recent studies argued that body modifications act as a means of self-construction and of communicating the self to others (Romanienko, 2011), by offering information about the individual's way of being and feeling (Cipolletta, Faccio, \& Berardi, 2010). (Doss \& Ebesu Hubbard, 2009) also argue that tattoos have the potential to be used for communicative purposes. The theory of self-construction argues that the self is continuously under construction throughout the lifespan. According to Baumeister (Baumeister, 1997), our sense of self is composed of schemas and concepts about our characteristics, which we shape through interactions with others. If tattoos are a form of communicating the self to others and serve to convey a certain image of oneself, the visibility of the body modification is also relevant, as it relates directly to the audience that individuals with BM are targeting. Bui and colleagues (Bui, et al., 2010) argue that it is necessary and legitimate to differentiate BM according to the degree of visibility and intimacy. Psychologically, intimate modifications may serve different functions and deserve further study (Caliendo, Armstrong, \& Roberts, 2005).

Body Modification and Dark Triad Personality: Associations have also been found between BM and antisocial personality traits such as narcissism, Machiavellianism, and subclinical psychopathy, which together are labeled the "Dark Triad" (Paulhus \& Williams, 2002). These three types of socially-averse personality traits are conceptually similar and have unsurprisingly been confused in previous research, as Furnham and colleagues point out in their meta-analysis (Furnham, Richards, \& Paulhus, 2013). To clarify the distinctions: narcissists are characterized by grandiosity, feelings of superiority over others, and a sense of entitlement (Emmons, 1984); Machiavellians are characterized by a sense of cynicism, by their lack of principles and readiness to manipulate others (Christie \& Geis, 1970); also see (Jones \& Paulhus, 2009) for a review); subclinical psychopathy is characterized by thrill-seeking, high impulsivity, and low empathy and anxiety (Paulhus \& Williams, 2002). Nathanson and colleagues (Nathanson, Paulhus, \& Williams, 2006) found that of the "Dark Triad", the most likely to be correlated with BM is subclinical psychopathy.

Due to the thrill-seeking nature of individuals within this category. This is consistent with an earlier study by Von Wiederhold (Von Wiederhold, 1995) that found individuals with BM scored significantly higher than individuals without BM on psychoticism and antisocial scales. Several studies have found that young adults and adolescents who possess BM also tend to engage in forms of misconduct that could be considered a form of thrill-seeking, including substance abuse and early sexual promiscuity (Brooks, Woods, Knight, \& Shrier, 2003), (Roberts, Auinger, \& Ryan, 2004), as well as illegal activities, gang affiliation, problem gambling, and school truancy (Deschesnes, Fines, \& Demers, 2006). Therefore, there is a strong indication that "Dark Triad" personality traits could correlate with BM. In the current study, we aim to investigate the relation between BM and narcissism, Machiavellianism, and subclinical psychopathy for a Romanian college student sample.

The Present Study: The current exploratory study starts from the findings of Paulhus \& Williams (Paulhus \& Williams, 2002), showing that BM is associated with subclinical psychopathy, narcissism, and Machiavellianism, and aims to investigate the personality correlates of body modifications in an Eastern European setting. It could be argued that BM has not yet entered the mainstream in the countries of the former Eastern Bloc and that their psychological correlates could be different from those discussed in research studies conducted in Western European or North American settings. This study aims to quantify the personality traits and the demographic data of tattooed individuals and to compare them with a control group of individuals without body modifications. In the framework of self-construction, BM can be conceptualized as a form of self-expression and self-presentation. Therefore, the study also investigates the location of BM on the body (visible vs. non-visible in a social/public context, corresponding to expressions of the public self/private self) to discuss its role as a self-construction and self-communication mechanism. The study also explores correlations between the BM's location/visibility and personality traits.

\section{Method}

Participants and Procedure: For data collection, a purposive convenience sampling technique was used. Self-administrated questionnaires were used on a sample of undergraduate students $(\mathrm{N}=154)$, with a 
subsample of the individuals that possessed tattoos $(\mathrm{N}=77)$ and one of the individuals without body modifications ( $\mathrm{N}=77$ ). The gender distribution was calculated for each subsample, having 40 women (mean age $\mathrm{M}=22.70, S D=3.51$ ) and 37 men (mean age $\mathrm{M}=25.62, S D=4.70$ ) in the BM subsample; and 52 women (mean age $\mathrm{M}=22.65, S D=4.49$ ) and 25 men (mean age $\mathrm{M}=23.56, S D=6.18$ ) in the non-BM subsample. The questionnaire was in Romanian, as all the respondents were Romanians. Before completion, the purpose of the study was briefly explained to the participants and informed consent was obtained. All participants were ensured about the confidentiality of the data and that it would be only used for research purposes.

\section{Measures}

Subclinical Psychopathy: We measured subclinical psychopathy using the Self-Report Psychopathy ScaleShort Form, SRP-SF (Paulhus, Neumann, \& Hare, in press). Respondents rated the degree to which they agree with 29 statements (from 1-'strongly disagree' to 5-'strongly agree.'). The scale consists of four subdimensions: interpersonal manipulation (includes characteristics such as pathological lying and manipulating), affective callousness (items relating to low empathy and a general lack of concern for other people), erratic lifestyle (characteristic related to recklessness and impulsivity), and overt antisociality (overt hostility and intentional aggression toward others). Sample items include "I've often done something dangerous just for the thrill of it." and "It's fun to see how far you can push a person before they catch on." A Romanian back-translated version of the scale was used, the reliability coefficients for the SRP-SF total score level $(\alpha=.84)$ being very good (Gordts, Uzieblo, Neumann, Van den Bussche, \& Rossi, 2017).

Machiavellianism: Machiavellianism was measured by using the Mach-IV scale (Christie \& Geis, 1970). It is a 20-item instrument using a 5-point Likert scale (1-'strongly disagree'; 5-'strongly agree'). Sample items include "It is hard to get ahead without cutting corners here or there." and "Anyone who completely trusts anyone else is asking for trouble." For the current study, a Romanian back-translated version of the scale was used, with good reliability ( $\alpha=.73$ ), as reported by Meyer (Meyer, 1992).

Narcissism: We measured narcissism through the Narcissistic Personality Inventory - NPI (Raskin \& Hall, 1979). It is an instrument with 40 items; for each item, respondents selected between two opposite statements, one of which indicates narcissism. Narcissism sample items include "I like to be the center of attention." and "I can make anybody believe anything I want them to". A Romanian back-translated version of the scale was used, having good reliability $(\alpha=.72)$ (Raskin \& Hall, 1981).

Presence of BM and Location on the Body: each participant was asked to indicate on an image of the human form the area where they possess body modifications, indicating one or several options between 1-6, according to the grid included over the image, and dividing the body into distinct areas. The areas were labeled as follows: 1 - head; 2 - neck, shoulders, upper arm, chest, upper back; 3 - arms and abdomen; 4 palms, genital area, upper thighs; 5 - lower thighs, knees, calves; 6 - lower calves, ankles, and feet). Participants that had several tattoos were asked to mark all the corresponding areas on the grid.

\section{Results and Discussion}

Dark Triad and Tattoos: We began by investigating the connection between the presence of BM and selfreported levels of psychopathy. We found the data to not be normally distributed, and therefore performed a Mann-Whitney U test, to compare individuals with BM and those without BM for each dimension of the SRP$\mathrm{SF}$ (table 1). We found that individuals with body modifications had significantly higher levels of psychopathy on the affective callousness $(U=2152, p=.003)$, erratic lifestyle $(U=1928, p=.000)$ and overt antisociality subscales $(U=2153, p=.003)$, as well as higher scores on the overall SRP-SF scale $(U=1892, p=.000)$. These findings are in line with previous results obtained by Nathanson and colleagues (Nathanson, Paulhus, \& Williams, 2006), who noted that, out of the Dark Triad personality traits, BM is more likely to be associated with subclinical psychopathy.

Visibility and Location of Body Modifications: We explored the connection between the visibility of the body modifications and dark triad personality correlates. One significant result, in this case, was that individuals with visible body modifications had a higher score on the affective callousness sub-dimension of 
the psychopathy scale $(U=1699, p=.000)$ and the overall self-reported subclinical psychopathy scale $(U=1538$, $p=.000)$.

Table 1: Mann- Whitney Test - Psychopathy

\begin{tabular}{lllll}
\hline & Affective Callousness & Erratic Lifestyle & Antisociality & SRP \\
\hline Mann-Whitney U & 2152.000 & 1928.000 & 2153.500 & 1892.500 \\
Wilcoxon W & 5155.000 & 4931.000 & 5156.500 & 4895.500 \\
Z & -2.949 & -3.759 & -2.950 & -3.876 \\
Asymp. Sig. (2-tailed) & .003 & .000 & .003 & .000 \\
\hline
\end{tabular}

A statistically significant negative correlation was found between the number of tattoos participants had and narcissism, indicating that more narcissistic individuals are also less inclined to alter their bodies through tattoos $\left(r_{s}=-.22, p=.050\right)$. One interpretation could be that individuals with high levels of narcissism feel less need to modify their bodies, due to already having a favorable body image as presented by (Jackson, Ervin, \& Hodge, 1992), (Lipowska \& Lipowski, 2015). One speculative explanation could be that, if tattoos express the individual's break from traditional behavioral norms, as suggested by (DeMello, 2003), then each additional such body modification serves as an instrument to communicate this break with social norms more resolutely.

Table 2: Mann-Whitney Test - Visibility

\begin{tabular}{lll}
\hline & Affective Callousness & SRP \\
\hline Mann-Whitney U & 1699.000 & 1538.500 \\
Wilcoxon W & 6850.000 & 6689.500 \\
Z & -3.734 & -4.330 \\
Asymp. Sig. (2-tailed) & .000 & .000 \\
\hline
\end{tabular}

However, there was no statistically significant difference for the erratic lifestyle dimension; we could speculate that individuals with visible body modifications are more prone to psychopathy behaviors that are meant to deflect social norms in ways that primarily affect those around them. The fact that only participants with higher levels of psychopathy chose to obtain modifications in a visible area could suggest that these alterations do have communicative value and can act as a means for identity construction. The location of body modification on the body proved to be significant. The fact that participants with visible BM did not have a statistically different score on the erratic lifestyle dimension, which primarily affects the individual himself and which predicts less severe antisocial behavior (Riopka, Coupland, \& Olver, 2015) could indicate that visible BM is used as a signal of defiance for community-oriented norms, more so than an indicator of irresponsibility, defiance of personal wellbeing and safety norms.

Following the observations made by other studies (Caliendo, Armstrong, \& Roberts, 2005); (Bui, et al., 2010) regarding the relevance of body modification location on the body, we compared Dark Triad personality scores for individuals with and without BM, for each area (1-6) included in the chart (figure 1). In the group of participants, the areas with the most BM were 2 (35 participants) and 3 (38 participants), followed by 4 (23 participants). The areas for which participants indicated the least amount of BM were 1 (16 participants), 6 (12 participants), and 5 (10 participants). Most participants had BM in several areas: 17 participants had BM in two areas, 8 participants had BM in three areas, and 7 participants had BM in four areas. Only 4 participants had BM in five areas, and only 2 participants had modifications in all six areas of the body chart. However, $29,6 \%$ of participants only had BM in one area. 


\section{Figure 1: Tattoo Body location}

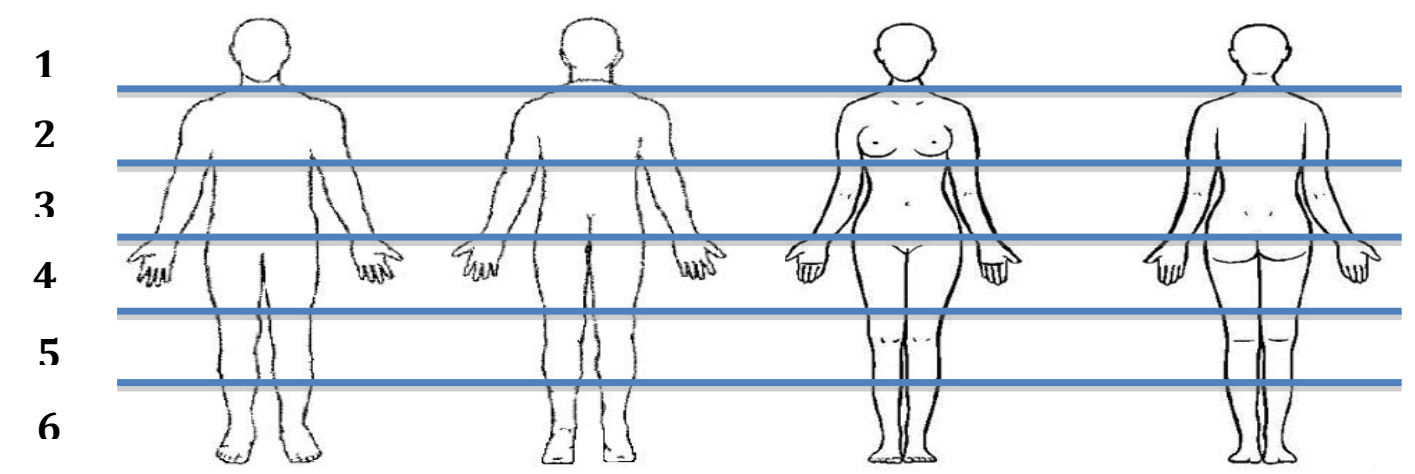

For the group of participants with BM (a total of 77), we conducted a Mann-Whitney U test for each of the six body areas included in the chart, comparing Dark Triad personality scores of participants with BM in the specific area and those without BM in the investigated area. We found that individuals who had BM in area 1 (head) had statistically significantly higher scores on the narcissism scale than individuals without BM in the said area $(U=1597, p=.024)$. The same statistically significant difference for narcissism was found in area 6 (lower calves, ankles, and feet) $(U=554, p=.037)$.

Table 3: Mann-Whitney Test - Area 1

\begin{tabular}{ll}
\hline & Narcissism \\
\hline Mann-Whitney U & 1597.000 \\
Wilcoxon W & 8618.000 \\
Z & -2.260 \\
Asymp. Sig. (2-tailed) & .024 \\
\hline
\end{tabular}

Table 4. Mann-Whitney Test - Area 6

\begin{tabular}{ll}
\hline & Narcissism \\
\hline Mann-Whitney U & 544.000 \\
Wilcoxon W & 622.000 \\
Z & -2.086 \\
Asymp. Sig. (2-tailed) & .037 \\
\hline
\end{tabular}

As discussed above, these are also the two areas where the least number of participants indicated having BM. One possible interpretation is that more narcissistic individuals have more favorable body images (Lipowska \& Lipowski, 2015) and, therefore, are less motivated to modify their bodies. Narcissism could also speculatively account for the decisions to obtain BM in areas of the body that are either very visible, making them difficult to conceal, or areas that are often covered, such as ankles and feet, thus making them very easy to conceal. These findings suggest a possible link between narcissism and impression management strategies for individuals with BM, and further studies should take this direction into account. Participants that had BM in area 2 (neck, shoulders, upper arm, chest, upper back) had statistically significant higher scores (table 5) both on the composite score of psychopathy $(U=1381, p=.002)$ and on the affective callousness dimension of the subclinical psychopathy scale than individuals without BM in that area $(U=1141, p=.000)$. This could suggest that individuals who chose to modify this area of the body might have lower levels of empathy and concern for other people.

Table 5: Mann-Whitney Test - Area 2

\begin{tabular}{lll}
\hline & SRP & Affective Callousness \\
\hline Mann-Whitney U & 1381.000 & 1141.500 \\
Wilcoxon W & 8521.000 & 8281.500 \\
Z & -3.026 & -4.075 \\
Asymp. Sig. (2-tailed) & .002 & .000 \\
\hline
\end{tabular}

For areas 3 (lower arms and abdomen) and 4 (palms, genital area, upper thighs), participants with modifications had a statistically significant higher score on the overt anti-sociality dimension of the SRP-SF scale, compared with individuals without BM in area $3(U=429, p=.002)$, and $4(U=353, p=.003)$. This finding suggests that there is indeed a need to further explore the significance of intimate area body modifications; few studies have investigated the motivations for getting this type of BM (Myers, 1992). 


\section{Conclusion and Limitations}

The findings of the current study support the conclusion of Nathanson and colleagues (Nathanson, Paulhus, \& Williams, 2006) that, of the Dark Triad trio, subclinical psychopathy is the most likely to be correlated with body modifications. The fact that the same finding was replicated in a different cultural context is of relevance and could suggest that the experience of obtaining BM is similar across cultures. We found that the group with BM (tattoos) had significantly higher scores on the overall SRP-SF on three of its four sub-scales, compared to individuals without body modifications. An increased number of tattoos was also significantly correlated with a higher level of anti-sociality. Participants with visible body modifications had significantly higher affective callousness and overall self-reported subclinical psychopathy levels, compared with individuals with non-visible alterations. Individuals with tattoos on the upper part of their bodies (below the head) had significantly higher levels of affective callousness, while individuals who had modifications on the lower half of their bodies, including lower arms, abdomen, palms, private area, and upper thighs had a significantly higher level of overt anti-sociality.

Though less prominent, associations between BM and narcissism were also found. Individuals who had higher levels of narcissism had fewer tattoos but were more likely to obtain body modifications on their head, ankles, and feet, compared to individuals with lower narcissism scores. One possible interpretation is that more narcissistic individuals have more favorable body images (Lipowska \& Lipowski, 2015) and, therefore, are less motivated to modify their bodies. However, the choice of preferred body area to modify for individuals with high narcissism is more difficult to interpret, the two selected areas being either very visible or very easy to conceal. Future studies should explore impression management techniques employed by individuals with high narcissism, and investigate the way narcissistic persons decide to acquire body modifications. Not finding strong Dark Triad personality differences between body modified and non-body modified individuals is even more important compared with the findings of studies on the perception of those possessing body modifications. Previous empirical studies reported that body-modified individuals were rated as possessing more negative personal characteristics than non-body-modified individuals (Degelmen \& Price, 2002), (Forbes, 2001), (Swami \& Furnham, 2007).

This discrepancy between self-reported and public-perception could be explained by the fact that body modification practices, especially tattoo, have already entered Eastern Europe into the cultural mainstream and may only represent fashion accessories. The limitations of the present study are clear. Self-reported data has its limitations, particularly on respondent honesty and the lack of social desirability of the Dark Triad personality scales used. However, the study did manage to identify a series of statistically significant correlations and differences that suggest BM has communicative value and can trace directions for future research. Subsequent studies should focus on the significance that individuals with body modifications attribute to their tattoos and the motivations for choosing the area of the body to modify. A mixed-methods approach could be of interest, combining interviews, for a deeper understanding of the way individuals perceive their tattoos, and surveys, to measure Dark Triad personality scores. What is missing in the field are empirical investigations that include not only measures of the dark side but also measures of a positive, growth-oriented side of human beings, the so-called Light Triad of personality (Kaufman, Yaden, Hyde, \& Tsukayama, 2019).

\section{Reference}

Baumeister, R. F. (1997). Identity, self-concept and self-esteem. In R. Hogan, J. Johnson, \& S. Briggs, Handbook of personality psychology (pp. 681-710). San Diego.

Braithwaite, R., Robillard, A., Woodring, T., Stephens, T. \& Arriola, K. J. (2001). Tattooing and body piercing among adolescent detainees: Relationship to alcohol and other drug use. Journal of Substance Abuse, 13(1-2), 5-16.

Brooks, T. L., Woods, E. R., Knight, J. R. \& Shrier, L. A. (2003). Body modification and substance use in adolescents: is there a link? Journal of Adolescent Health, 32(1), 44-49.

Bui, E., Rodgers, R., Cailhol, L., Birmes, P., Chabrol, H. \& Schmitt, L. (2010). Body piercing and psychopathology: a review of the literature. Psychotherapy and psychosomatics, 79(2), 125-129. 
Caliendo, C., Armstrong, M. L. \& Roberts, A. E. (2005). Self-reported characteristics of women and men with intimate body piercings. Journal of Advanced Nursing, 49(5), 474-484.

Caroll, S. T., Riffenburg, R. H. \& Myhre, E. B. (2002). Tattoos and body piercing as indicators of adolescent risktaking behaviors. Pediatrics, 109(6), 1021-1027.

Christie, R. \& Geis, F. L. (1970). Studies in Machiavellianism. New York: Academic Press.

Cipolletta, S., Faccio, E. \& Berardi, S. (2010). Body piercing: does it modify self-construction? A research with repertory grids. Personal Construct Theory and Practice, 7, 85-95.

Degelmen, D. \& Price, N. D. (2002). Tattoos and ratings of personal characteristics. Psychological Reports, 90, 507-514.

DeMello, M. (2003). Bodies of Inscription: A cultural history of the modern tattoo community. Duke: Duke University Press.

Deschesnes, M., Fines, P. \& Demers, S. (2006). Are Tattooing and Body Piercing Indicators of Risk-Taking Behaviours Among High School Students? Journal of Adolescence, 29(3), 379-393.

Doss, K. \& Ebesu Hubbard, A. S. (2009). The communicative value of tattoos: The role of public selfconsciousness on tattoo visibility. Communication research reports, 26(1), 62-74.

Emmons, R. A. (1984). Factor analysis and construct validity of the Narcissistic Personality Inventory. Journal of Personality Assessment, 48(3), 291-300.

Favazza, A. R. (1996). Bodies under siege: Self-mutilation and body modification in culture and psychiatry. Baltimore, MD: The John Hopkins University Press.

Forbes, G. B. (2001). College students with tattoos and piercing: Motives, family experiences, personality factors, and perceptions by others. Psychological Reports, 89, 774-786.

Furnham, A., Richards, S. C. \& Paulhus, D. L. (2013). The Dark Triad of Personality: A 10-year review. Social and Personality Psychology Compass, 7(3), 199-216.

Gordts, S., Uzieblo, K., Neumann, C., Van den Bussche, E. \& Rossi, G. (2017). The validity of the Self-Report Psychopathy Scale (SRP-III Full and Short Versions) in a Community Sample. Assessment, 24(3), 308325.

Jackson, L. A., Ervin, K. S. \& Hodge, C. N. (1992). Narcissism and body image. Journal of Research in Personality, 26(4), 357-370.

Jones, D. N. \& Paulhus, D. L. (2009). Machiavellianism. In M. R. Leary, \& R. H. Hoyle, Handbook of Individual Differences in Social Behavior (pp. 93-108). New York: Guilford.

Kaufman, S. B., Yaden, D. B., Hyde, E. \& Tsukayama, E. (2019). The Light vs. Dark Triad of Personality: Contrasting two very different profiles of human nature. Frontiers in psychology, 10, 467.

Lipowska, M. \& Lipowski, M. (2015). Narcissism as a moderator of satisfaction with body image in young women with extreme underweight and obesity. PLOS ONE, 10(5).

Meyer, H. D. (1992). Norms and self-interest in ultimatum bargaining: The prince's prudence. Journal of Economic Psychology, 13(2), 215-232.

Myers, J. (1992). Nonmainstream body modification: Genital piercing, branding \& cutting. Journal of Contemporary Ethnography, 21(3), 267-306.

Nathanson, C., Paulhus, D. L. \& Williams, K. M. (2006). Personality and misconduct correlates of body modification and other cultural deviance markers. Journal of Research in Personality, 40(5), 779-802.

Paulhus, D. L. \& Williams, K. M. (2002). The Dark Triad of personality: Narcissism, Machiavellianism, and psychopathy. Journal of Research in Personality, 36(6), 556-563.

Paulhus, D. L., Neumann, C. S. \& Hare, R. (in press). Manual for the Hare Self-Report Psychopathy Scale. Toronto: Multi-Health Systems.

Post, R. S. (1968). The Relationship of Tattoos to Personality Disorders. The Journal of Criminal Law, Criminology, and Police Science, 59(4), 516-524.

Raskin, R. N. \& Hall, C. S. (1979). A Narcissistic Personality Inventory. Psychological Reports, 590.

Raskin, R. N. \& Hall, C. S. (1981). The Narcissistic Personality Inventory: alternative form reliability and further evidence of construct validity. Journal of personality assessment, 45(2), 159-162.

Raspa, R. F. \& Cusack, J. (1990). Psychiatric implications of tattoos. American Family Physician, 41(5), 14811486.

Riopka, S. J., Coupland, R. \& Olver, M. E. (2015). Self-reported psychopathy and its association with criminal cognition and antisocial behavior in a sample of university undergraduates. Canadian Journal of Behavioral Science/ Revue Canadienne des sciences du comportement, 47(3), 216-225. 


\section{Journal of Social and Development Sciences (ISSN 2221-1152)}

Vol. 11, No. 4, pp. 7-14, December 2020

Roberts, T. A., Auinger, P. \& Ryan, S. A. (2004). Body piercing and high-risk behavior in adolescents. Journal of Adolescent Health, 34(3), 224-229.

Romanienko, L. A. (2011). Nonverbal Communication. Body Piercing and Identity Construction: A Comparative Perspective. New York: Wroclaw.

Rooks, J. K., Roberts, D. J. \& Scheltma, K. (2000). Tattoos: the relationship to trauma, psychopathology and other myths. Minnesota Medicine, 83(7), 24-27.

Stirn, A., Hinz, A. \& Brahler, E. (2006). Prevalence of tattooing and body piercing in Germany and perception of health, mental disorders, and sensation seeking among tattooed and body-pierced individuals. Journal of Psychosomatic Research, 60(5), 531-534.

Swami, V. \& Furnham, A. (2007). Unattractive, promiscuous, and heavy drinkers: Perceptions of women with tattoos. Body Image, 4, 343-352.

Swami, V., Gaughan, H., Tran, U. S., Kuhlmann, T., Stieger, S. \& Voracek, M. (2015). Are tattooed adults really more aggressive and rebellious than those without tattoos? Body image, 15, 149-152.

Tate, J. C. \& Shelton, B. L. (2008). Personality correlates of tattooing and body piercing in a college sample: The kids are alright. Personality and Individual Differences, 45(4), 281-285.

Von Wiederhold, M. W. (1995). Piercing the body: A symbolic voice, a psychoanalytic view of contemporary body modification. Doctoral dissertation. Berkeley, California: Wright Institute Graduate School of Psychology.

Wohlrab, S., Stahl, J., Rammsayer, T. \& Kappeler, P. M. (2007). Differences in personality characteristics between body-modified and non-modified individuals: associations with individual personality traits and their possible evolutionary implications. European Journal of Personality, 21(7), 931-951. 